\title{
Voice for science
}

\section{Academics and industrialists have been discussing the role of $R \& D$ in Pakistan. Azim Kidwai reports}

PAKISTAN has remained in a state of political flux since the general election last March when Mr Zulfiqar Ali Bhutto's Peoples' Party won a doubtful victory. The army takeover and the introduction of martial law in early July has also had its sobering effects; but in the face of this and the prospect of another, perhaps emotional, election next October, Pakistan's R\&D effort seems unusually resilient.

This is reflected in the fact that the consensus reached by important representatives from education, science, technology and industry at the National Seminar on Cooperation between Universities, Research Institutes and Industry, recently held in Karachi, may have significant effects on the promotion of R\&D in Pakistan. The seminar was unique in that it was organised by the Federation of Pakistan Chambers of Commerce and Industry and was attended, among others, by three vice-chancellors, the Chairman of the Pakistan Council of Scientific and Industrial Research, the Secretary of the Ministry of Science, several heads of research institutes and many leading industrialists. It was, in fact, a sequel to a UNIDO Adhoc Expert Group meeting on the same subject, which was held in Vienna last December and in which Pakistan participated.

The Karachi moot, however, reflected new trends in Pakistan one of which was that the private sector of industry, which had hitherto been largely apathetic towards scientific and industrial research, had started showing awareness of its importance. A fruitful outcome of the three-day deliberations was the formation of a National Research Utilisation Board by the Chambers of Commerce and Industry, consisting of representatives from universities, research institutes and industry itself. It is to promote industries based on indigenous research.

The main bottleneck so far in making use of research has been the absence of any proper mechanism to rope industry into the R\&D effort. The entrepreneurs in industry have largely settled for 'turn-key' jobs on proven products and for technology developed by foreign firms. The element of challenge and the calculated gamble in using produots and processes developed locally has rarely been acceptable to the industrialist.

The position now appears to have changed considerably with the tight balance of payments making it imperative to exploit indigenous raw materials and local technological talent. The dearth of foreign exchange has had its repercussions on the industrial sector. For the first time, industrialists are coming round to the view that the limited resources of the country call for an organised approach based on self-reliance and for the mobilisation of the meagre $R \& D$ resources. The technology which will be applied, however, will need to be appropriate to the physical, human and capital resources available.

Until now, there have been two weak points in the structure. The universities have been dominated by academics and have contributed almost nothing to applied research and the development of industry; and there has been a lack of interest on the part of industry in the government's R\&D effort. The recommendations which came out of the seminar are for more collaboration between industry and research institutions and industry and the universities.

Another suggestion to be accepted at the seminar was that research and development centres should be gradually created within industrial enterprises and that the $R \& D$ function should be part of feasibility studies and the design of new large plants. To promote applied research in the universities, the Universities Grants Commission and the Pakistan Science Foundation are likely to give liberal financial support for collaborative research, while the Government may help by providing industry with incentives, such as tax exemption, for sponsoring research projects. Research in the universities suffers from inadequate funds; if more money were available, they could work for technological progress as well as pure knowledge.

Dr Salimuzzaman Siddiqui, a chemist, stressed the point that pure and applied research cannot easily be demarcated. So far as problem solving is concerned, priorities cannot be allocated under rigidly defined categories and there should be a massive but carefully phased multidisciplinary programme. Most of the participants felt strongly about another point raised by Dr Siddiqui, namely that Pakistan was spending barely $0.2 \%$ of its gross national product on $\mathrm{R} \& \mathrm{D}$ compared to $2-4 \%$ in many advanced countries: there was need for a major change.

\section{Desert song}

LIKE the United Nations, which organised an intergovernmental conference on desertification in Nairobi earlier this month, China has been taking an interest in the problems of desert control. Over recent years two national conferences on desert control have been held and several major works on aspects of desertification have been published, including "An outline of Chinese deserts' and 'Summary of mass experience in China's desert control'. Two further works, 'Control of sand destructive to farmland' and 'Protecting railways against sand' are to be published soon.

Using the findings reported in these publications as guidelines, prefectures, counties and communes in six provinces and autonomous regions have drawn up their own plans to combat or even reverse descrtification taking into account local conditions. The now established causes of desertification.... unplanncd irrigation, excessive tree felling, overcultivation, overgrazing, with drought being a condition but not a fundamental cause-are supported in ancient Chinese records. Measures taken to tame deserts include:

- planting wind resistant shrubs on the windward side of land threatened by encroaching deserts and tall trees near farmland. When the wind blows at average speeds, the length of the protected area is some twenty times the depth of the forest shelter belts. Crisscrossing tree belts in oases provides further protection against the wind.

creating new oases by building reservoirs to store seasonal flood water from streams and lakes and using melted snow from the mountains or underground water to irrigate the reclaimed land before planting trees to protect it.

- developing pasture land for animal husbandry in deserts with fixed sand dunes or only interspersed shifting sand. Forage bases can be established on flat land in between sand dunes where water resources are relatively abundant.

Such measures are important especially as $11 \%$ of China's total land area, about one million square kilometres, is desert. Just over half of this is dune desert, the rest being gravel and other types. The Academia Sinica runs a desert research institute which studies desert distribution and type, the processes which form them, their natural conditions and ways of combating destructive sandstorms and using water and soil resources in sandy areas and in reclaimed land. It also publishes a quarterly journal Desert Research. In addition, the state has set up experimental forest farms and twenty demonstration stations for desert control. Many species of plants, which will survive in the desert, have been grown at the stations.

T. B. Tang 